\title{
Acquired equivalences between auditory stimuli in dolphins (Tursiops truncatus)
}

\begin{abstract}
This study investigated whether dolphins would show evidence of equivalence class formation between auditory stimuli. Bottlenose dolphins were trained to press one or other of two response levers depending on which one of four auditory stimuli had been previously presented. Once they had learned the initial discriminations, the stimulus-lever contingencies was repeatedly reversed. Within any given session, however, pressing of one lever always led to reward with one set of two tones and pressing the other lever led to non-reward with an alternative set of two tones. After sufficient experience with this response reversal procedure, the dolphins spontaneously chose the same levers they had first learned to be correct with one of the across-set stimulus pairs when later in the session they were presented with the other of the acrossset stimulus pairs. They thus demonstrated that they had associated the tones belonging to the two sets within two separate functional classes. It is discussed why the dolphins succeeded with auditory stimuli when they had previously failed in a similar task with visual stimuli.
\end{abstract}

Key words Bottlenose dolphins - Auditory discriminations $\cdot$ Response re-assignments $\cdot$ Acquired equivalence $\cdot$ Concept formation

\section{Introduction}

The cognitive capacities of dolphins are widely believed to be of an exceptional order. Their elaborate show performances together with their complex social behaviour and a high degree of encephalization have generally been

L. von Fersen

Tiergarten Stadt Nürnberg, 90480 Nürnberg, Germany

J. D. Delius $(\varangle)$

Allgemeine Psychologie, Universität, Konstanz,

78465 Konstanz, Germany

e-mail: juan.delius@uni-konstanz.de,

Fax: +49-7531-883184 taken as indicative of a comparatively superior intelligence (Roitblat and Fersen 1992; Siemann et al. 1998; but see Güntürkün and Fersen 1998). Indeed, several experimental studies have shown them to be capable of remarkable cognitive feats. For example, Fersen et al. (1993) showed that dolphins were capable of acquiring a generalized categorization of symmetric and asymmetric visual shapes, and Herman et al. (1989; see also Herman et al. 1994) demonstrated that they could be trained on a generalized similar-dissimilar stimulus discrimination which transferred across the visual and auditory domains (see also Pack and Herman 1995).

In this report we are concerned with the question of whether dolphins might show a substantial reassignment transfer effect. This transfer effect was brought up by Lea (1984) in connection with a key question in comparative cognition. He argued that one might talk about concepts in animals if it could be shown that they could associate stimuli of a certain class with each other and not only with a given response and/or reinforcement as is the case when animals are said to categorize sets of stimuli. Such interstimulus association could be demonstrated by first training animals to discriminate between two sets of stimuli by rewarding responses to one set whilst not rewarding responses to the other set and then retraining to discriminate between two subsets of these stimuli using reversed reinforcement allocations. An intra-class, inter-stimulus association would be demonstrated if the animals spontaneously transferred their newly reversed response to the remaining subsets of stimuli. This kind of acquired equivalence between stimuli indeed came to be considered as the defining element of true concept formation by some authors, foremost among them Herrnstein (1990). But it is also a fact that other authors, well represented by Thompson (1995) take a more conservative stand on this issue.

Regardless of the dispute about whether inter-stimulus associations are a valid indicator of concept formation or not, these associations have latterly established themselves as a topic of intrinsic interest. Acquired equivalences (or mediated generalizations, Wasserman et al. 
1992) of this nature turn up in several learning contexts besides that occupying us here and have merited a theoretical treatment of their own (Hall 1996; see also Delamater 1998). This theory depends importantly on interaction processes between memorized stimulus representations. However, because the mainly comparative results that will be reported contribute little to these rather subtle arguments, they will not be elaborated further here.

When Lea's reinforcement re-assignment procedure was first tried out on pigeons, it did not yield much evidence of any inter-stimulus association (e.g. Bhatt and Wasserman 1989; Fersen and Lea 1990). More recently Astley and Wasserman (1998) tried a somewhat different response reassignment procedure. Pigeons had to learn to co-categorize four subsets of pictures into two separate classes by requiring them to respond to two different response keys for reward. The birds were then retrained to respond on a new, differently located pair of keys employing two of the picture subsets. Subsequently they were tested for a corresponding response transfer with the two remaining picture subsets. Only a modest reassignment transfer effect was found. Vaughan (1988), however, was markedly more successful with an improved repeated reinforcement reversal procedure. Pigeons learned to repeatedly discriminate scenic slides divided into two sets under serial reinforcement reversal conditions. Eventually, experience with just a few initial slides of each set after a reversal was sufficient for the pigeons to respond correctly to all the remaining slides of these sets. The birds were said to have classified the stimuli into two functional classes because as soon as they detected that some of the slides of the sets had changed their significance, they spontaneously transferred the adequate response to the remainder of them.

Because Vaughan (1988) used numerous and complex stimuli it was difficult to analyse the equivalence formation process in any detail. Delius et al. (1995) explored whether a corresponding transfer could also be demonstrated with fewer and simpler stimuli. Pigeons were trained to discriminate between two pairs of colour stimuli, $\mathrm{A} 1+\mathrm{B} 1-$ and $\mathrm{A} 2+\mathrm{B} 2-$, using a simultaneous discrimination procedure. Once they had reached a preset learning criterion the reinforcement allocations were reversed (A1-B2+, A2-B2+). This was done several times. In later test sessions first only one of the stimulus pairs was presented in this reversed format (leading pair, say A1+B1-) until the birds responded correctly to it. Subsequently the other pair (trailing pair) was initially presented in unreinforced test trials (A2oB2o) and only afterwards in correspondingly reinforcement-reversed trials $(\mathrm{A} 2+\mathrm{B} 2-)$ as the leading trial. The pigeons showed a somewhat better performance with the initial trailing pairs than with the first leading pair during these post-reversal test sessions, revealing that they had built up some inter-stimulus association. Further experiments with this few-stimuli design using an improved leading-trailing procedure and pairs of visual shapes yielded somewhat better evidence of reinforcement re-assignment transfer in pigeons (Siemann and Delius 1998; see also Delius et al. 2000 a). Neverthe- less, the training needed was still considerable and the effects obtained were still less than overwhelming.

Assuming that dolphins are probably more cognitively gifted than pigeons, would they perhaps show a better ability with an elementary reassignment task of the kind just described? Dolphins were accordingly trained to discriminate two pairs of tones using a reward, no-reward, successive procedure. One response lever led to reward with one set of two stimuli and another lever led to reward with the other set of two stimuli. When they had learned this task the lever-to-stimuli correspondence was reversed, and so several times until the animals become proficient with the reversal procedure. With increasing reversal experience it was expected that during the presentation of the second pair of stimuli (trailing trials) the dolphins would begin to spontaneously choose the lever that corresponded to the lever-stimuli contingency valid during the presentation of the first pair of stimuli (leading trials).

\section{Methods}

Subjects

Two show-trained and experimentally experienced adult bottlenose dolphins (Tursiops truncatus) belonging to the dolphinarium of the Nürnberg Zoo participated in this experiment. Anke was a 15 -year-old female and Nemo an 8-year-old male. Both animals lived together with three other dolphins in a large communal pool. The experiment was conducted with one animal at the time in a circular 15-m-diameter subsidiary pool.

\section{Apparatus and stimuli}

The apparatus consisted of an underwater loudspeaker (Diatran) placed about $25 \mathrm{~cm}$ from the pool's edge and $15 \mathrm{~cm}$ below the water's surface. Two response levers were installed at the sides of the loudspeaker. A positioning ball floating at the end of a thin overwater boom was located $1.5 \mathrm{~m}$ away and in front of the loudspeaker. Four sinusoidal tones of different frequencies served as the stimuli. These tones, each lasting $10 \mathrm{~s}$, were originally produced with a frequency generator (Keithley), recorded with a taperecorder (Grundig) so as to be of approximately equal loudness to the human ear, and presented to the dolphins with the aid of the same taperecorder. They were assigned to two sets of stimuli, set A consisting of stimuli $\mathrm{A} 1,6 \mathrm{kHz}$, and $\mathrm{A} 2,9 \mathrm{kHz}$, and set $\mathrm{B}$ consisting of stimuli B1, $7.5 \mathrm{kHz}$, and B2, $10 \mathrm{kHz}$. Note that, if anything, the tones used were less similar within sets than between sets. Their frequencies, in particular, were not in any way harmonically related (Ralston and Herman 1995). Four pairs of discriminative stimuli were assembled from these stimuli, two uncrossed pairs A1B1, A2B2 and two crossed pairs A1B2, A2B1.

\section{Procedure}

The dolphins were trained to discriminate the stimuli using a successive stimulus presentation procedure. Each trial within this procedure began with the experimenter giving a hand signal requesting the dolphin to position itself by the stationing ball while facing the loudspeaker. Once the animal had obeyed this order the experimenter started the tape-recorder and one of the stimuli sounded from the loudspeaker. When the experimenter, who could hear the stimuli via earphones, gave a brief whistle signal, immediately afterwards the dolphin swam towards the loudspeaker and pressed one of the response levers. If the animal pressed the lever defined 
as correct for the tone just presented the experimenter sounded a continuous whistle tone and rewarded the dolphin with a fish. Upon responses to the incorrect lever the experimenter produced a discontinuous whistle sound and issued no fish, but hand-signalled for the dolphin to reposition itself for a repetition of the same trial (correction trial). This correction procedure only ended when the dolphin chose the correct lever. Correction trials did not count towards the performance scores mentioned later. The inter-trial intervals lasted approximately $30 \mathrm{~s}$. During the inter-trial interval the loudspeaker was switched off while the experimenter positioned the tape ready for the next stimulus presentation according to a previously prepared list. Each session consisted of 32 trials (not counting correction trials). Sessions were daily except on weekends. To control for unintended artefactual cues occasional sessions were run by a dolphin trainer who was uninformed as to the stimuli presented in any trial and the responses expected of the dolphin. The experimenter remained hidden and only issued verbal instructions as to the kind of feedback that the dolphin was to receive after it had chosen a lever. At no time was the dolphin's level of performance at all affected by this control procedure.

For the initial sessions of the experiment the left lever was defined as correct for the A class sounds and the right lever for the B class sounds. The trial-by-trial sequencing (omitting correction trials) of A or B class stimuli was determined by a quasi-random sequence (Gellermann 1933). Within each session the first ten trials involved presentations of stimuli out of one of the stimulus pairs, called the leading pair (during the first session of the experiment it was pair A1B1). Starting with the 11th trial the other pair, called the trailing stimulus pair (during the first session it was the pair A2B2), was presented for the next 10 trials. However, from the fourth training session onwards the 11th, 12th and 13th trials were not reinforced. During these trials responses to either lever led directly to the inter-trial interval without the experimenter issuing any whistle signal or fish reward feedback. Responses to these stimuli led directly to the next trial. Note that the lever choice corresponding to the 14th trial also took place before the animal had received any feedback concerning trailing stimulus choices. The last 12 trials of the session involved a randomised presentation of leading and trailing pairs of stimuli. For each session it was quasirandomly determined whether the $\mathrm{A} 1 \mathrm{~B} 1$ pair or the $\mathrm{A} 1 \mathrm{~B} 2$ pair served as the leading pair and the $\mathrm{A} 2 \mathrm{~B} 2$ or the $\mathrm{A} 2 \mathrm{~B} 1$ pair served as the trailing pair, or vice versa. At the beginning of the experiment, whenever an animal had successfully completed a pair of successive sessions with an average $80 \%$ or more correct choices, the next session involved a reversal of the contingencies between the stimuli and the levers. Thus, during the first reversal of the experiment the right lever was correct with the A class tones and the left lever with the B class tones. When the animals again attained the criterion with this new reversed stimulus-response contingency, the next session involved an assignment reversal of the levers, and so on. From the 7 th reversal onwards the reversals were instituted whenever the animals completed a single session with $80 \%$ or more correct choices. The experiment continued until each dolphin achieved an at least $80 \%$ correct discrimination performance across the cumulated first four trailing post-reversal trials of seven consecutive reversal sessions. That meant a cumulative total of 28 trial choices prior to any feedback specific to the trailing pairs.

\section{Results}

The animals had little difficulty in learning the initial discriminations and also adapted well to the repeated reversals procedure. The performance of both animals improved quite steadily on both counts as the training progressed. Anke needed 10 and Nemo 11 sessions to achieve the $80 \%$ correct discrimination criterion for the first time. Initially the first sessions after reversals led to less than $40 \%$ correct choices over all 32 trials. By the 3 rd reversal (Nemo) or 5 th reversal (Anke) the dolphins had begun to make 40-60\% correct choices during the post-reversal sessions. By the 10 th reversal (Anke) or the 22 nd reversal (Nemo) the dolphins were producing $60 \%$ or more correct choices during the first post-reversal sessions. Anke needed 68 sessions involving 17 reversals and Nemo 87 sessions involving 22 reversals to complete the criterion defined earlier relating to the first four post-reversal trailing trials which terminated the experiment.

Table 1 summarises the choice behaviour with the leading and trailing pairs shown by the dolphins at the beginning and at the end of experiment. It is obvious that for the first trial after a reversal the animals persisted in choosing the levers according to their pre-reversal assignment, this yielding close to $0 \%$ correct choices. At the beginning of training they only managed $40 \%$ or less with the $3 \mathrm{rd}-7$ th leading trials. But it is also obvious that with experience they had learned to adapt to the reversal, giving over $70 \%$ correct responses with the 3 rd-7th leading pair trials towards the end of the experiment. It is also obvious that at the beginning of training the animals were not really able to transfer the performance achieved with the leading pair trials to the initial trailing pair trials, giv-
Table 1 Summary of Nemo's (top line of panels) and Anke's (bottom line of panels) choice behaviour with the initial leading pair trials and trailing pair trials during the first sessions after the initial reversals and after the final reversals

\begin{tabular}{|c|c|c|c|c|}
\hline & \multicolumn{2}{|c|}{$\begin{array}{r}\text { First } 7 \text { reversals (1st-7th) } \\
(1 \mathrm{st}-7 \mathrm{th})\end{array}$} & \multicolumn{2}{|c|}{$\begin{array}{r}\text { Last } 7 \text { reversals (16th-22nd) } \\
\text { (11th-17th) }\end{array}$} \\
\hline & $\begin{array}{l}\text { Correct } \\
\text { choices }\end{array}$ & $\%$ Correct & $\begin{array}{l}\text { Correct } \\
\text { choices }\end{array}$ & $\%$ Correct \\
\hline 1st Leading trial & $\begin{array}{l}0 \text { of } 7 \\
0 \text { of } 7\end{array}$ & $\begin{array}{l}0 \% \\
0 \%\end{array}$ & $\begin{array}{l}1 \text { of } 7 \\
0 \text { of } 7\end{array}$ & $\begin{array}{r}14 \% \\
0 \%\end{array}$ \\
\hline 2nd Leading trial & $\begin{array}{l}3 \text { of } 7 \\
2 \text { of } 7\end{array}$ & $\begin{array}{l}43 \% \\
29 \%\end{array}$ & $\begin{array}{l}3 \text { of } 7 \\
4 \text { of } 7\end{array}$ & $\begin{array}{l}43 \% \\
57 \%\end{array}$ \\
\hline 3rd-10th Leading trials & $\begin{array}{l}25 \text { of } 63 \\
19 \text { of } 63\end{array}$ & $\begin{array}{l}40 \% \\
30 \%\end{array}$ & $\begin{array}{l}48 \text { of } 63 \\
46 \text { of } 63\end{array}$ & $\begin{array}{l}76 \% \\
73 \%\end{array}$ \\
\hline 1st-4th Trailing trials & $\begin{array}{l}8 \text { of } 28 \\
7 \text { of } 28\end{array}$ & $\begin{array}{l}29 \% \\
25 \%\end{array}$ & $\begin{array}{l}25 \text { of } 28 \\
23 \text { of } 28\end{array}$ & $\begin{array}{l}89 \% \\
82 \%\end{array}$ \\
\hline 5th-10th Trailing trials & $\begin{array}{l}25 \text { of } 35 \\
19 \text { of } 35\end{array}$ & $\begin{array}{l}71 \% \\
54 \%\end{array}$ & $\begin{array}{l}29 \text { of } 35 \\
28 \text { of } 35\end{array}$ & $\begin{array}{l}83 \% \\
80 \%\end{array}$ \\
\hline
\end{tabular}


ing less than $30 \%$ correct choices. Towards the end of the experiment, however, they showed more than $80 \%$ correct choices with the as yet unreinforced 1st-4th trailing pair choices. Nemo chose correctly in 25 out of 28 trials and Anke in 23 out of 28 trials (both binomial tests, $P<0.01$ ). This indicates that what they had learned about the lever contingencies during the leading pair trials was transferring fully to the pre-feedback trailing pair trials. Indeed, the reinforcements associated with the subsequent 5th10th trailing trials did not lead to a further improvement of performance.

\section{Discussion}

The key issue was whether after extensive leading-trailing pair reversal training, the experience with the response reversal of only one discriminatory stimulus pair would suffice to bring about lever choice reversal with respect to the other stimulus pair. Since the first three trials of the trailing stimulus pairs (the 11th-13th trials of each session) were run under extinction conditions, any learning during the trials up to and including the 14th trial (the first reinforcement only occurring after the choice response of this trial) can be excluded. The response contingency transfers during these latter trials are thus indicative of equivalence class formation. Both dolphins did very well towards the end of training, making an average of 24 out of 28 choices correctly. Notice that an account of the grouping of the stimuli in terms of overlapping generalization gradients (Mackintosh 2000), i.e. on the basis of frequency similarities. cannot apply here, as the stimuli to be associated alternated on the frequency dimension by being $6 \mathrm{kHz}$ and $9 \mathrm{kHz}$ within one set and $7.5 \mathrm{kHz}$ and $10 \mathrm{kHz}$ within the other set. Any generalization due to tone frequency similarities would thus necessarily work against the intra-set transfer that was demonstrated. The stimuli, as already remarked, were also not in any harmonic relationship that could have vitiated this latter argument. A transfer strategy based on relational frequency discrimination was not possible because the uncrossed and crossed discrimination pairs involved opposite stimulus-frequency relationships.

The level of transfer achieved by the dolphins was unquestionably higher than that obtained with an analogous four-stimulus reinforcement reversal design in pigeons (Delius et al. 1995; Siemann and Delius 1998). While the dolphin's pre-feedback performance with trailing pairs was well above random choice level that of the pigeons barely fell above that chance level. The possibility that the different methods of successive discrimination and response reassignment used with the dolphins and of simultaneous discrimination and reinforcement reassignment used with the pigeons might have been responsible for the performance difference is unlikely. As already mentioned, Astley and Wasserman (1998) found that pigeons also yielded an only weak performance transfer with a successive discrimination and response reassignment procedure.
One should however not conclude from this that pigeons are generally poor at acquiring equivalence classes. Using a more exacting but also more complex reinforcement reversal procedure (M. Jitsumori, M. Siemann, M. Lehr and J. D. Delius, unpublished work; see also Delius et al. 2000 a) succeeded in showing that pigeons were capable of an appreciable reinforcement re-assignment transfer and moreover, that they were capable of building up networks of stimulus equivalencies. Indeed, the pigeons were shown to be capable of even extrapolating new, untaught stimulus equivalence relationships from these networks.

It is worth pointing out that the dolphin results reported here contrast with those of a preliminary experiment ( $\mathrm{L}$. von Fersen, unpublished work). It employed a similar overall design but used a simultaneous, two-stimulus procedure involving visual stimuli. Two bottlenose dolphins, an adult female, Emy, and the male that participated in the present experiment, Nemo, were the subjects. Instead of tones the stimuli presented were a circle (A1), a square (A2) a rectangle (B1) and an ellipse (B2). These stimuli were projected as approximately $10 \times 10 \mathrm{~cm}$ white shapes on a dark background using two slide projectors. The projection took place down two adjacent wide-bore plastic tubes. These were occluded at their submerged ends with two circular $25-\mathrm{cm}$-diameter plastic projection screens. The dolphins thus viewed the stimuli from under water. Each of the screens was equipped with a response lever. The discrimination paradigm was a simultaneous one, i.e. during any given trial the animal always had to choose between a positive and a negative stimulus. Otherwise the procedure was closely similar to the one used for the experiment reported here. During the first session after a reversal a leading pair was shown for six to nine trials before the trailing pair was followed for several trials. In this instance all the trials involved reinforcement so that only the choices during first leading pair trial and the first trailing pair trial represented no-feedback choices. We stress that the animals had no particular difficulties in learning to discriminate the visual stimuli as such (see also Fersen et al. 2000). But even after 125 sessions involving a total of 23 reversals (Nemo) and 152 sessions involving 20 reversals (Emy) they showed no evidence whatsoever of transferring the choice behaviour learned with the leading pairs to the trailing pairs. During the last eight post-reversal sessions both dolphins chose correctly only three times, i.e. they did not even achieve the chance choice level. They clearly had not been able to group the stimuli according to their common response/reinforcement contingencies as was the case in the present experiment where evidence of transfer was quite apparent by the 10th or 15 th reversal.

Disregarding the possibility that the disparity in results across the auditory and visual modalities might be due to the subtle methodological differences, it seems reasonable to ascribe them to an adaptive specialization. Although it is the case that in other experiments bottlenose dolphins showed quite good cross-modal transfer of object recognition between the echoic (auditory) and visual modalities (Herman et al. 1989; see also Pack and Herman 1995), it 
is also true that in accordance with their excellent adaptation to their aquatic environment the dolphins' auditory system is arguably more highly developed than their visual system (Nachtigall 1986). In this they differ from, for example, the more terrestrial sea lions who have in fact been shown to be capable of visual equivalence formation (Schusterman and Kastak 1993). It is possible that in dolphins the situation is analogous to that reported for rats, in which the so-called learning set or learning-to-learn performance is comparatively poor when the stimuli to be discriminated are visual but relatively good when the discriminanda are odours. This even though, the rats did manage to learn the components of the multiple discrimination task at about comparable levels of proficiency in both modalities (Slotnick and Katz 1974). Perhaps the dolphins' performance dichotomy with equivalence formation also illustrates the modularity of the cognitive apparatus recently highlighted by Shettleworth (1998). Animals are thought to have evolved mainly specialised "intelligences" which are largely dedicated to limited situational domains. These are likely to be those in which selection for advanced cognitive abilities were particularly persistent in the species' evolutionary past (Delius et al. 2000b).

Acknowledgements We are grateful to the Director of Nürnberg Zoo, Dr. Peter Mühling, for much institutional help and to the personnel of the dolphinarium, especially Mr. Hans-Jürgen Klinckert, for extensive assistance. We thank the Deutsche Forschungsgemeinschaft for grant support, Drs. Martina Siemann and Mark Cleaveland (Konstanz) for helpful comments and Jessica Grante (Exeter) for assistance with the English text.

\section{References}

Astley SL, Wasserman EA (1998) Novelty and functional equivalence in superordinate categorization by pigeons. Anim Learn Behav 26:125-138

Bhatt RS, Wasserman EA (1989) Secondary generalization and categorization in pigeons. J Exp Anal Behav 52:213-224

Delamater AR (1998) Associative mediational processes in the acquired equivalence and distinctiveness of cues. J Exp Psychol Anim Behav Proc 24:467-482

Delius JD, Ameling M, Lea SEG, Staddon JER (1995) Reinforcement concordance induces and maintains stimulus associations in pigeons. Psychol Rec 45:283-297

Delius JD, Jitsumori M, Siemann M (2000a) Stimulus equivalencies through discrimination reversals. In: Heyes C, Huber L (eds) Evolution of cognition. MIT Press, Cambridge, pp 103122

Delius JD, Siemann M, Emmerton J, Xia L (2000b) Cognitions of birds as products of evolved brains. In: Roth G, Wullimann MF (eds) Brain, evolution and cognition. Spectrum, Heidelberg/ Wiley, New York, pp 451-490

Fersen L von, Lea SEG (1990) Category discrimination by pigeons using five polymorphous features. J Exp Anal Behav 54:69-84

Fersen L von, Manos C, Goldovsky B, Roitblat H (1993) Dolphin detection and conceptualization of symmetry. In: Thomas JA, Kastelein RA, Supin Y (eds) Sensory systems and behaviour of aquatic mammals. Plenum, New York, pp 753-763
Fersen L von, Schall U, Güntürkün O (2000) Visual lateralization of pattern discrimination in the bottlenose dolphin (Tursiops truncatus). Behav Brain Res 107:177-181

Gellermann LW (1933) Chance orders of alternating stimuli in visual discrimination experiments. J Genet Psychol 42:206-208

Güntürkün O, Fersen L von (1998) So wenig graue Zellen; ein Mythos wird angetastet. Rubin 1:6-13

Hall G (1996) Learning about associatively activated stimulus representations: implications for acquired equivalence and perceptual learning. Anim Behav Learn 24:233-255

Herman L, Hovancik J, Gory J, Bradshaw G (1989) Generalization of visual matching in the bottlenose dolphin (Tursiops truncatus): evidence of invariance of cognitive performance with visual or auditory materials. J Exp Psychol Anim Behav Proc 15:124-136

Herman LM, Pack AA, Wood AM (1994) Bottlenose dolphin can generalize rules and develop abstract concepts. Mar Mamm Sci 10:70-80

Herrnstein RJ (1990) Levels of stimulus control, a functional approach. Cognition 37:133-166

Lea SEG (1984) In what sense do pigeons learn concepts? In: Roitblat HL, Bever T, Terrace HS (eds) Animal cognition. Erlbaum, Hillsdale, pp 263-277

Mackintosh NJ (2000) Abstraction and discrimination. In: Heyes CM, Huber L (eds) The evolution of cognition. Cambridge, MIT Press, pp 123-141

Nachtigall PE (1986) Vision, audition, and chemoreception in dolphins, and other marine mammals. In: Schusterman R, Thomas J, Wood F (eds) Dolphin cognition and behavior: a comparative approach. Erlbaum, London, pp 79-114

Pack AA, Herman LM (1995) Sensory integration in the bottlenosed dolphins: immediate recognition of complex shapes across the senses of echolocation and vision. J Acoust Soc Am 98:722-732

Ralston JV, Herman LM (1995) Perception and generalization of frequency contours by a bottlenose dolphin (Tursiops truncatus). J Comp Psychol 109:268-277

Roitblat L, Fersen L von (1992) Comparative cognition: representations and processes in learning and memory. Annu Rev Psychol 43:671-710

Schusterman RJ, Kastak D (1993) A California sea lion (Zalophus californianus) is capable of forming equivalence relations. Psychol Rec 43:823-839

Shettleworth SJ (1998) Cognition, evolution, and behavior. New York University Press, Oxford

Siemann M, Delius JD (1998) Induction of stimulus associations by reinforcement concordances in pigeons. In: Elsner N, Wehner R (eds) Göttingen Neurobiology Report 1998. Thieme, Stuttgart, p 447

Siemann M, Fersen L von, Delius JD (1998) Kognition bei Tieren In: Irle E, Markowitsch HJ (eds) Vergleichende Psychobiologie. Enzyklopädie der Psychologie. Hogrefe, Göttingen, pp 695738

Slotnick BM, Katz HM (1974) Olfactory learning-set formation in rats. Science 185:796-798

Thompson RKR (1995) Natural and relational concepts in animals. In: Roitblat HL, Meyer JA (eds) Comparative approaches to cognitive science. MIT Press, Cambridge, pp 175-224

Vaughan W (1988) Formation of equivalence sets in pigeons. J Exp Psychol Anim Behav Proc 14:36-42

Wasserman EA, DeVolder CL, Coppage DJ (1992) Non-similarity-based conceptualization in pigeons via secondary or mediated generalization. Psychol Sci 3:374-379 